\title{
SISTEM PREDIKSI TINGKAT PENGANGGURAN DI PROVINSI MALUKU MENGGUNAKAN ANFIS (ADAPTIVE NEURO FUZZY INFERENCE SYSTEM)
}

\author{
Dorteus L. Rahakbauw ${ }^{1 *}$, Muh. Iskandar Tanassy ${ }^{2}$, Berni P. Tomasouw ${ }^{3}$ \\ 1,2,3 Jurusan Matemtika FMIPA, Universitas Pattimura \\ Jalan Ir. M. Putuhena, Kampus Unpatti, Poka, Ambon, Indonesia \\ e-mail: ${ }^{1 *}$ lodewyik@gmail.com ; ${ }^{2}$ iskandartanassy@gmail.com ; 3 bernypebo@yahoo.co.id \\ Corresponding Author *
}

\begin{abstract}
Abstrak
Pengangguran merupakan salah satu permasalahan yang belum terselesaikan dengan baik sampai saat ini meskipun sudah dilakukan berbagai upaya untuk menurunkan jumlah tingkat pengangguran. Tingkat pengangguran masih mengalami kenaikan dari tahun ke tahun. Pada penelitian ini akan dibuat sistem prediksi tingkat pengangguran menggunakan ANFIS (Adaptive Neuro Fuzzy Inference System). Data yang digunakan bersumber dari BPS yaitu data Angkatan kerja tahun 2001-2017. Data ini meliputi data Jumlah Penduduk Usia Kerja (JPUK), input Jumlah Angkatan Kerja (JAK) dan input Jumlah Pekerja (JP), yang masing masing dibagi dalam tiga kategori: rendah, sedang, dan tinggi; Untuk pelatihan Algoritma ANFIS ada 3 input yaitu input JPUK, JAK dan JP dengan satu output Jumlah Pengangguran (JPg). Untuk mendapatkan struktur ANFIS yang baik dan keanggotaan yang akan dipilih dilakukan pelatihan data untuk tahun 20012007 lalu dipilih membership function dengan error terkecil sebagai keanggotaan parameter yang diuji. Kemudian data tahun 2008-2017 diuji menggunakan membership function tersebut dan menghasilkan sebuah sistem prediksi yang nantinya menjadi sistem yang digunakan sebagai prediksi. Hasil penelitian diperoleh rata-rata presentasi error sistem prediksi tingkat pengangguran sebesar 4,49\%. Yang mengindikasikan metode ini layak dipertimbangkan sebagai opsi penyelesaian masalah pengangguran di provinsi Maluku.
\end{abstract}

Kata Kunci: ANFIS, logika fuzzy, pengangguran.

\section{PREDICTION SYSTEM OF UNEMPLOYMENT RATE IN MALUKU PROVINCE USING ANFIS (ADAPTIVE NEURO FUZZY INFERENCE SYSTEM)}

\begin{abstract}
Unemployment is one of the problems that has not been resolved properly until now despite efforts made to reduce the number of unemployment rates. The unemployment rate is still rising from year to year. In this research will make prediction system of unemployment rate using ANFIS (Adaptive Neuro Fuzzy Inference System). The data used is sourced from BPS, namely labor force data for 2001-2017. This data includes data on the Number of Working Age Population (JPUK), input of Labor Force Amount (JAK) and input Number of Workers (JP), each of which is divided into three categories: low, medium, and high; For training ANFIS Algorithm there are 3 inputs, namely JPUK, JAK and JP inputs with one output Amount of Unemployment (JPg). To get a good ANFIS structure and membership to be selected, data training was conducted for 2001-2007 and the membership function was chosen with the smallest error as the membership parameter tested. Then the 2008-2017 data was tested using the membership function and produced a predictive system which later became a system used as a prediction. The results of the study obtained an average presentation of system errors predicting the unemployment rate of $4.49 \%$. Which indicates this method is worth considering as an option to solve the unemployment problem in province of Moluccas.
\end{abstract}

Keywords: ANFIS, fuzzy logic, prediction, unemployment. 


\section{PENDAHULUAN}

Saat ini pengangguran merupakan salah satu permasalahan yang sangat menyita perhatian pemerintah dan masyarakat di Provinsi Maluku. Pengangguran umumnya disebabkan karena jumlah angkatan kerja atau pencari kerja tidak sebanding dengan lapangan pekerjaan. Pada tahun 2016 jumlah angkatan kerja pada awal tahunnya yaitu 733.337 jiwa sedangkan yang menganggur sebanyak 51.164 jiwa lalu mengalami peningkatan pada tahun 2017 jumlah angkatan kerja pada awal tahunnya yaitu 769.108 jiwa mengalami peningkatan sebanyak 35.771 jiwa sedangkan yang menganggur sebanyak 59.745 jiwa [2]. Maluku merupakan provinsi dengan Tingkat Pengangguran Terbuka (TPT) tertinggi pada Agustus 2017. Menurut data pada Badan Pusat Statistik (BPS) jumlah pengangguran di Provinsi Maluku mencapai 65.735 orang atau 9,29 persen dari total angkatan kerja sebanyak 707.796 orang. Angka ini bertambah di bulan Agustus 2017 sebesar 13.372 orang dari jumlah pada bulan Agustus 2016. Berbanding terbalik dengan angkatan kerja dan bekerja yang berkurang sebesar 48.725 orang menjadi 642.061 orang [5].

Berdasarkan permasalahan tersebut diperlukan Informasi tingkat pengangguran dari waktu ke waktu sebagai acuan untuk mengambil kebijakan dalam mengatasi permasalahan pengangguran tersebut. Pendekatan memprediksi jumlah pengangguran dianggap baik untuk menyelesaikan masalah bertambahnya jumlah pengangguran di provinsi Maluku. Prediksi adalah proses perkiraan atau pengukuran untuk diproyeksikan suatu nilai dengan memanfaatkan persamaan matematika dan statistika, prediksi juga berarti hasil perhitungan berdasarkan data dan analisa apapun baik ilmiah maupun non ilmiah dan dapat dilakukan secara kualitatif maupun kuantitatif. Perkiraan merupakan pendapat yang berdasarkan dugaan perasaan tanpa bukti nyata, perkiraan secara kualitatif biasanya menggunakan pendapat para ahli. Secara kuantitatif menggunakan metode statistik dan matematik [9]. ANFIS (Adaptive Neuro Fuzzy Inference System) adalah metode prediksi yang berkembang dalam membangun sistim prediksi suatu permasalahan, Metode ANFIS merupakan metode yang efektif untuk sebuah prediksi karena tingkat kesalahannya lebih kecil dibandingkan dengan menggunakan metode ANN (Artificial Neural Network) [2]. Selain itu, tingkat keakuratan dari model ANFIS dipengaruhi oleh jumlah dan kualitas dari sampel data [5].

Karena metode ANFIS dianggap baik maka penulis tertarik untuk menggunakan ANFIS untuk dalam membangun Sistem Prediksi Tingkat Pengangguran di Provinsi Maluku.

\section{TINJAUAN PUSTAKA}

\subsection{Gambaran umum ANFIS}

Adaptive Neuro Fuzzy Inference System (ANFIS) merupakan penggabungan dari logika fuzzy dan jaringan saraf tiruan (JST). Logika fuzzy memiliki kelebihan dalam memodelkan aspek kualitatif dari pengetahuan manusia dan proses pengambilan keputusan dengan menerapkan basis aturan (rules). JST memiliki kelebihan dalam mengenali pola, belajar dan berlatih dalam menyelesaikan suatu permasalahan tanpa memerlukan pemodelan matematik. Serta dapat bekerja berdasarkan data historis yang dimasukkan kepadanya dan dapat melakukan prediksi kejadian yang akan datang berdasarkan data-data tersebut. Sehingga ANFIS memiliki kemampuan keduanya [7].

\subsection{Arsitektur ANFIS}

Misalkan input terdiri atas $x_{1, t}$ dan $x_{2, t}$ dan sebuah output $x_{t}$ dengan aturan model Sugeno orde 1. Orde 1 dipilih dengan pertimbangan kesederhanaan dan kemudahan perhitungan. Model Sugeno orde 1 dengan dua aturan fuzzy if-then adalah sebagai berikut:

Rule 1: if $x_{1, t}$ is $A_{1}$ and $x_{2, t}$ is $B_{2}$ then $f_{1}=p_{1} \cdot x_{1, t}+q_{1} \cdot x_{2, t}+r_{1}$

Maka Rule 1: if $x_{1, t}$ is $A_{1}$ and $x_{2, t}$ is $B_{2}$ then $f_{2}=p_{2} \cdot x_{1, t}+q_{2} \cdot x_{2, t}+r_{1}$

Dengan $A_{i}$ dan $B_{i}$ adalah nilai-nilai kenggotaan merupakan label linguistik (seperti "kecil" atau "besar"), $p_{i}, q_{i}$ dan $r_{i}$ adalah parameter konsekuen [6]. 


\subsection{Jaringan ANFIS}

Adaptive Neuro Fuzzy Inference System atau ANFIS adalah jaringan syaraf yang fungsinya sama dengan system inferensi fuzzy. Pada ANFIS, proses belajar pada jaringan neural dengan sejumlah data berguna untuk memperbaharui parameter-parameter system inferensi fuzzy. Jaringan ANFIS yang ditunjukkan pada gambar berikut [4]:

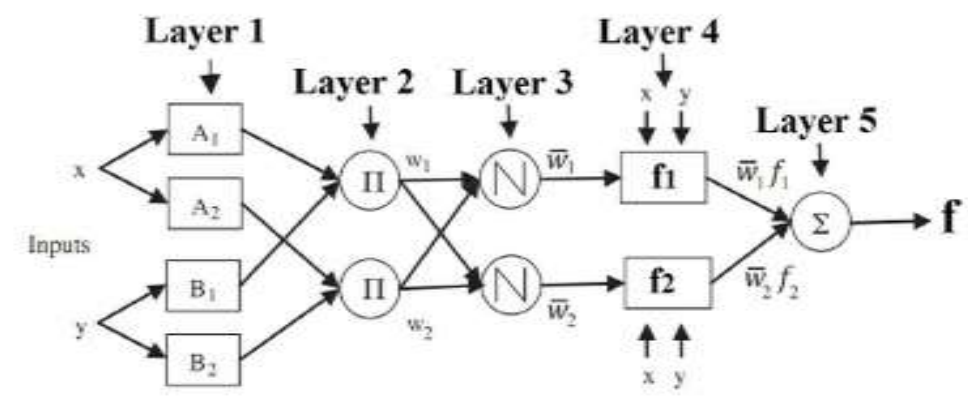

Gambar 1. Model Jaringan ANFIS.

\section{Lapisan 1:}

Lapisan ini merupakan fuzzyfikasi. Pada lapisan ini tiap neuron adaptif terhadap parameter suatu aktivasi. Output dari tiap neuron berupa derajat keanggotaan yang diberikan oleh membership function input. Misalkan membership function Trapesium diberikan sebagai :

$$
\mu_{\text {trapesium }}(x ; a, b, c, d)=\left\{\begin{array}{cc}
0, & x \leq a \\
\frac{x-a}{b-a}, & a \leq x \leq b \\
1, & b \leq x \leq c \\
\frac{d-x}{d-c}, & c \leq x \leq d \\
0, & d \leq x
\end{array}\right.
$$

Dengan $x$ adalah input dalam hal ini $x=\left(x_{1, t}, x_{2, t}\right)$ dan $\{a, b, c$, dan $d\}$ adalah parameter-parameter. Parameter-parameter ini biasanya disebut sebagai parameter premis.

\section{Lapisan 2:}

Lapisan ini berupa neuron yang tetap dan ditandai sebagai $\Pi$, yang dimana output-nya merupakan hasil kali dari semua masukan atau input yang masuk:

$$
O_{2}=w_{i}=\mu_{A i} \mu_{B i}
$$

Biasanya digunakan operator AND (dan; penghubung). Hasil perhitungan ini disebut firing strength dari sebuah aturan. Tiap output merepresentasikan kekuaatan dari setiap rule.

\section{Lapisan 3:}

Tiap neuron pada lapisan ini beupa neuron tetap dan ditandai sebagai $N$. Neuron ke- $i$ mengkalkulasi rasio dari kekuatan rule ke-i ke semua jumlah rule's firing strenghts pada lapisan kedua, sebagai berikut:

$$
O_{4}=\bar{w}_{i}=\frac{w_{i}}{w_{1}+w_{2}}
$$

Hasil perhitungan ini disebut normalized firing strength.

\section{Lapisan 4:}

Lapisan ini berupa neuron-neuron yang merupakan neuron adaptif terhadap suatu output, sebagai berikut:

$$
O_{4, i}=\bar{w}_{i} f_{i}=\bar{w}_{i}\left(p_{i} x_{1, t}+q_{i} x_{2, t}+r_{i}\right)
$$

Dengan $\bar{w}_{i}$ adalah normalized firing strength pada lapisan ketiga dan $p_{i}, q_{i}$ dan $r_{i}$ adalah parameterparameter pada neuron tersebut. Parameter-parameter ini biasa disebut parameter konsekuen. 


\section{Lapisan 5 :}

Lapisan ini berupa neuron tunggal dan ditandai dengan $\sum$ merupakan hasil penjumlahan seluruh output pada lapisan keempat yang dianggap sebagai signal input:

$$
\sum_{i} \bar{w}_{i} f_{i}=\frac{\sum_{i} w_{i} f_{i}}{\sum_{i} w_{i}}
$$

\section{METODE PENELITIAN}

Data yang digunakan dalam penelitian ini berupa data sekunder yang diperoleh dari pangkalan data BPS, yaitu data tentang Angkatan Kerja tahun 2001-2017. Data yang digunakan meliputi data JPUK, JAK, dan JP sebagai variabel-variabel yang mempengaruhi jumlah pengangguran di suatu provinsi [BPS]. Data dibagi menjadi dua yaitu data pelatihan tahun 2001-2007 dengan 3 variabel linguistik: tinggi, sedang dan rendah pada setiap variabel input berdasarkan membership function Trapesium dan data uji tahun 2008-2017. Berikut ini tahapan prediksi dengan ANFIS:

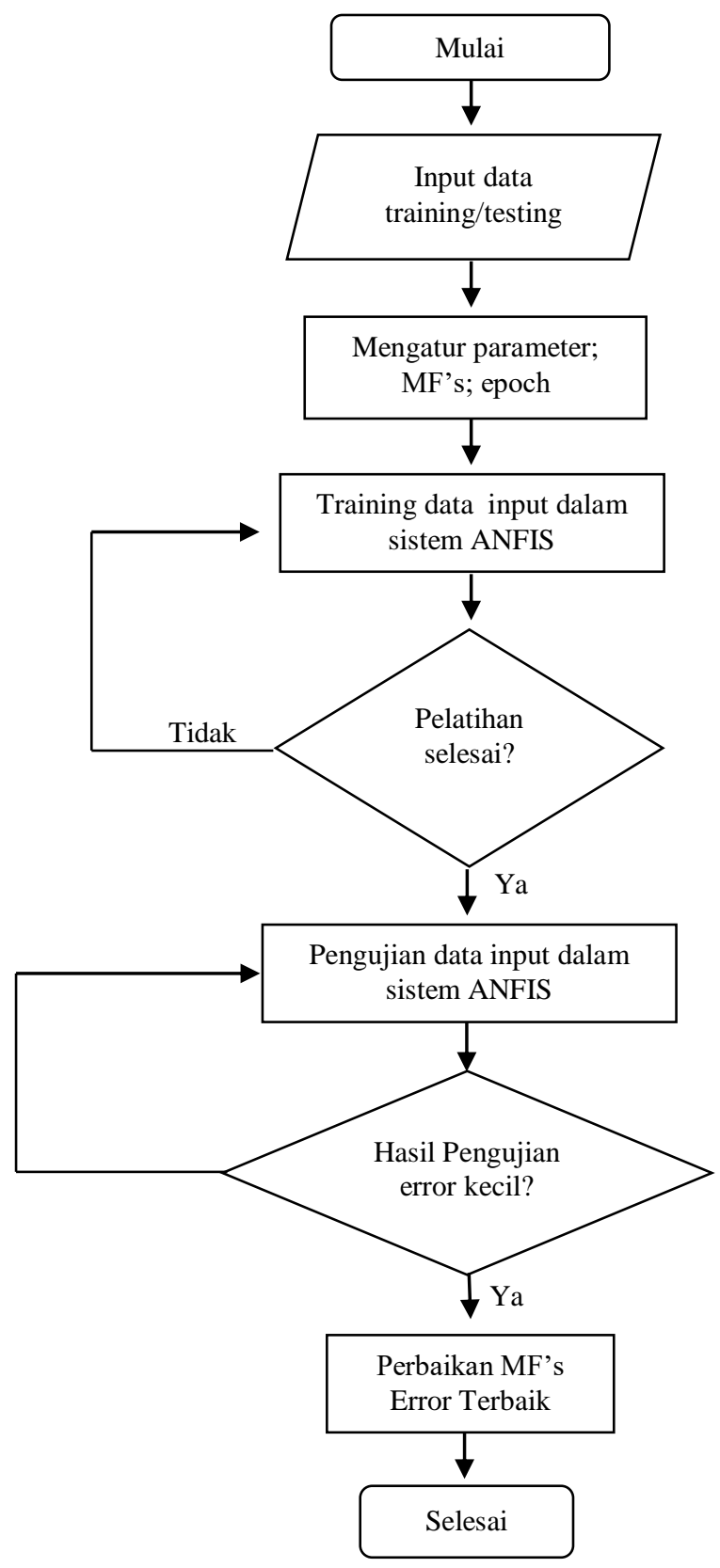

Gambar 2. flowchart prediksi ANFIS 
Proses awal penerapan ANFIS untuk memprediksi jumlah pengangguran adalah penetapan variabel input, membership function, epoch, dan selanjutnya dilakukan proses training dan testing sampai ditemukan model data terbaik setelah itu, model dengan rules yang diterapkan dalam proses prediksi dilakukan untuk validasi dari performa ANFIS sampai mencapai selisih error terkecil. Gambar 2 menunjukkan flowchart prediksi ANFIS.

\section{HASIL DAN PEMBAHASAN}

Dilakukan pengujian error dari Generate FIS (Fuzzy Inference System) dengan menggunakan MF Trapesium (Bahu) yang dibagi kedalam 3 keanggotaan yaitu Rendah, Sedang dan Tinggi MFs [3 3 3] dan epoch 10 yang menghasilkan error 0,1662. Dipilih MFs [3 33 3] artinya terdapat tiga input yang masing-masing terbagi atas tiga membership function.

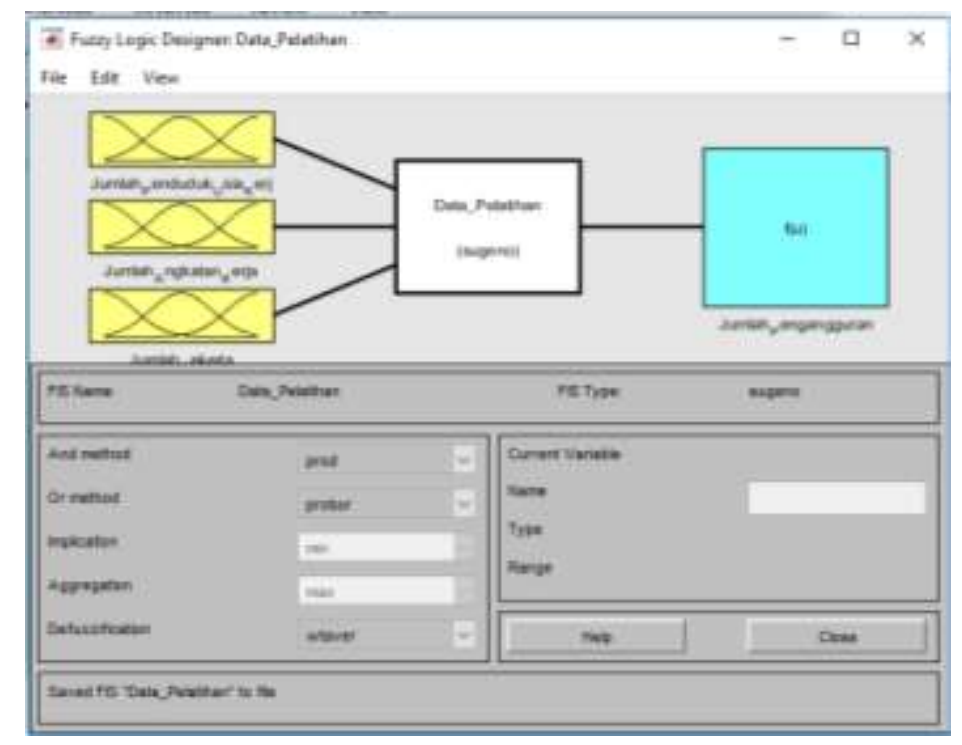

Gambar 3. FIS Editor.

Untuk pelatihan Algoritma ANFIS disusun FIS dimana ada 3 variabel input yaitu JPUK, JAK dan JP, yang masing-masing memiliki 3 variabel linguistik (Tinggi, medium, rendah) dengan satu output JPg (gambar 3). Dalam penerapan Algoritma ANFIS digunakan data pelatihan (2001-2007) dan data uji (2008-2017).

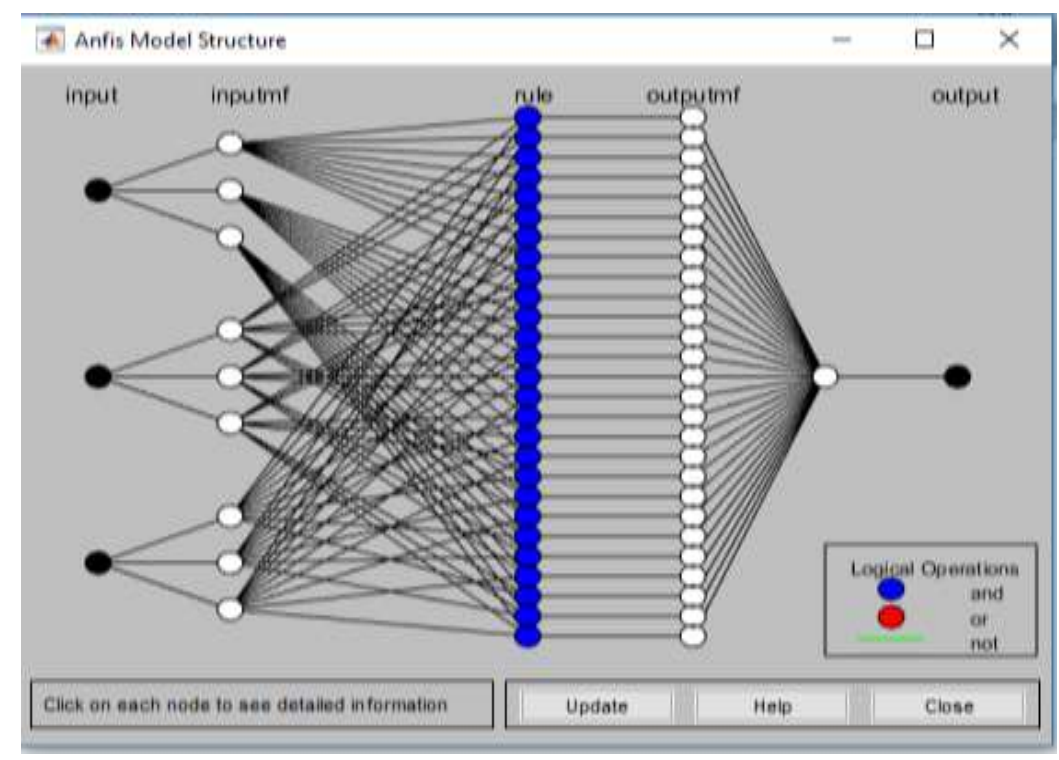

Gambar 4. Model Struktur (Arsitektur) ANFIS 
Untuk output keanggotaannya constant karena hasil dari inferensi fuzzy metode Sugeno merupakan konstanta. Untuk memprediksi digunakan 3 variabel input yang masing-masing memiliki 3 variabel linguistik menghasilkan $3^{3}=27$ Rules yang digunakan saat membangun Rules output metode ini.

Berikut tabel hasil pengujian algoritma ANFIS pada sistem prediksi tingkat pengangguran dengan menggunakan data uji yang kemudian dihitung presentase error dari masing-masing data dengan menggunakan rumus presentase error:

$$
\% \text { error }=\frac{\text { loutput asli-output prediksi } \mid}{\text { output asli }} \times 100 \%
$$

Tabel 1. Hasil Pengujian

\begin{tabular}{|rrrrrrr|}
\hline Tahun & JPUK & JAK & JP & JPeng & JPeng(output) & Error (\%) \\
\hline 2008 & 890.217 & 559.239 & 499.555 & 59.684 & $5,97 \times 10^{4}$ & 0,027 \\
\hline 2009 & 850.844 & 536.030 & 533.015 & 3.015 & $3,04 \times 10^{3}$ & 0,83 \\
\hline 2010 & 979.714 & 651.339 & 586.430 & 64.909 & $5,76 \times 10^{4}$ & 11,23 \\
\hline 2011 & 1.010 .287 & 701.893 & 650.112 & 51.781 & $5,18 \times 10^{4}$ & 0,037 \\
\hline 2012 & 1.035 .915 & 659.953 & 610.362 & 49.591 & $576 \times 10^{4}$ & 16,15 \\
\hline 2013 & 1.079 .849 & 668.721 & 602.429 & 66.292 & $6,48 \times 10^{4}$ & 2,25 \\
\hline 2014 & 1.103 .643 & 672.304 & 601.651 & 70.653 & $7,14 \times 10^{4}$ & 1,06 \\
\hline 2015 & 1.128 .137 & 727.259 & 655.063 & 72.196 & $7,22 \times 10^{4}$ & 0,006 \\
\hline 2016 & 1.151 .962 & 743.149 & 690.786 & 52.363 & $5,61 \times 10^{4}$ & 7,14 \\
\hline 2017 & 1.163 .910 & 769.108 & 709.363 & 59.745 & $5,61 \times 10^{4}$ & 6,1 \\
\hline \multicolumn{7}{c}{ Rata-rata persentase error } \\
\hline
\end{tabular}

Setelah dilakukan pengujian pada sistem prediksi tingkat pengangguran menggunakan GUI yang ada pada Software Matlab, hasil yang diperoleh memiliki presentase error yang tidak terlalu besar dengan rata-rata error yaitu sebesar 4,49\%. Untuk masing-masing data yang dimasukan presentase error terbesar ada pada data ke-5 pada data uji dengan masukan berturut-turut untuk Jumlah Penduduk Usia Kerja, Jumlah Angkatan Kerja dan Jumlah Pekerja sebesar 1.035.915, 659.953 dan 610.362 dengan hasil output $5,76 \times 10^{4}$ sementara target yang diinginkan yaitu 49.591 memiliki presentasi error sebesar $16,15 \%$.

\section{KESIMPULAN}

Dari hasil pengujian algoritma ANFIS pada sistem prediksi tingkat pengangguran diperoleh kesimpulan setelah melakukan proses pelatihan Algoritma ANFIS dengan menggunakan 3 variabel input dengan masing-masing variabel terdiri dari 10 data dengan menggunakan MFs Trapesium dan menggunakan rule sebanyak 27 rule serta keanggotaan output yang konstan diperoleh sistem prediksi tingkat pengangguran dengan presentasi rata-rata error sebesar 4,49\%.

\section{Daftar Pustaka}

[1] A. Fitriah, A. M. Abadi, "Aplikasi Model Neuro Fuzzy Untuk Prediksi Tingkat Inflasi Di Indonesia”, Prosiding Seminar Nasional Matematika dan Pendidikan Matematika UNY, ISBN : 978-979-16353-6-3, 2011.

[2] B. P. Statistik, “Keadaan Ketenagakerajan Maluku,” BPS, Ambon, 2017.

[3] C. Dewi, D. P. Kartikasari, Y. T. Mursityo, "Prediksi Cuaca Pada Data Time Series Menggunakan Adaptive Neuro Fuzzy Inference System (ANFIS)", Jurnal Teknologi Informasi dan Ilmu Komputer (JTIIK) UB, Vol. 1, No. 1, April 2014.

[4] J. S. R. Jang, “ANFIS: Adaptive Neuro Fuzzy Inference System,” IEEE Trans. on System, Man, and Cybernetics, pp. 655-685, 1993. 
[5] Katadata, "Agustus 2017, Pengangguran Maluku Tertinggi", 7 November 2017. [Online]. Available: https://databoks.katadata.co.id/datapublish/2017/11/07/agustus-2017-pengangguranmaluku-tertinggi. [Diakses 15 Januari 2018].

[6] L. Fausett, Fundamentals of Neural Network: Architectures, Fundamentals, and Applications, New Jersey: Prentice-Hall, Inc., 1994.

[7] N. Azizah, K. Adi, A. Widodo, "Metode Adaptive Neuro Fuzzy Inference System (ANFIS) untuk Prediksi Tingkat Layanan Jalan”, Jurnal Sistem Informasi Bisnis Undip, Vol.3 No.3 , 2013.

[8] S. Kusumadewi, Fuzzy Multi-Attribut Decision Making (Fuzzy MADM), Yogyakarta: Graha Ilmu Yogyakarta, 2006.

[9] S. Halim, Diktat Time Series Analysis, Surabaya: Petra, 2006. 
